\title{
Correction to: Unexpected Benefit from Alpelisib and Fulvestrant in a Woman with Highly Pre-treated ER-Positive, HER2-Negative PIK3CA Mutant Metastatic Breast Cancer
}

\author{
Griet Hoste ${ }^{1}$ (1) - Laurence Slembrouck ${ }^{2}$ - Lynn Jongen ${ }^{2} \cdot$ Kevin Punie $^{2,3} \cdot$ Tom Matton $^{4} \cdot$ Sara Vander Borght ${ }^{5,6}$. \\ Isabelle Vanden Bempt ${ }^{6}$. Johan Menten ${ }^{1,7}$. Hans Wildiers ${ }^{2,3} \cdot$ Giuseppe Floris $^{4,8} \cdot$ Carlos Arteaga ${ }^{9} \cdot$ Patrick Neven $^{1,2}$
}

Published online: 12 January 2019

(c) Springer Nature Switzerland AG 2019

\section{Correction to: Clinical Drug Investigation (2018) 38(11):1071-1075 https://doi.org/10.1007/s40261-018-0696-3}

Conflict of interest, which previously read:

The authors declare that they have no competing interests.
Should read:

Dr. Arteaga serves on an Advisory Board for Novartis and was a consultant for AstraZeneca from 2015 to 2016. All other authors declare that they have no competing interests.

The original article can be found online at https://doi.org/10.1007/ s40261-018-0696-3.

Griet Hoste

griet.hoste@uzleuven.be

Laurence Slembrouck

laurence.slembrouck@uzleuven.be

Lynn Jongen

lynn.jongen@uzleuven.be

Kevin Punie

kevin.punie@uzleuven.be

Tom Matton

tom.matton@uzleuven.be

Sara Vander Borght

sara.vanderborght@uzleuven.be

Isabelle Vanden Bempt

isabelle.vandenbempt@uzleuven.be

Johan Menten

johan.menten@uzleuven.be

Hans Wildiers

hans.wildiers@uzleuven.be

Giuseppe Floris

giuseppe.floris@uzleuven.be

Carlos Arteaga

Carlos.Arteaga@utsouthwestern.edu

Patrick Neven

patrick.neven@uzleuven.be
1 Department of Gynaecology and Obstetrics, University Hospitals Leuven, KU Leuven, University of Leuven, Herestraat 49, 3000 Louvain, Belgium

2 Department of Oncology, University Hospitals Leuven, KU Leuven, University of Leuven, 3000 Louvain, Belgium

3 Department of General Medical Oncology, University Hospitals Leuven, KU Leuven, University of Leuven, 3000 Louvain, Belgium

4 Department of Radiology, KU Leuven, University Hospitals Leuven, 3000 Louvain, Belgium

5 Department of Pathology, KU Leuven, University Hospitals Leuven, 3000 Louvain, Belgium

6 Department of Human Genetics, University Hospitals Leuven, KU Leuven, University of Leuven, 3000 Louvain, Belgium

7 Department of Radiotherapy, University Hospitals Leuven, KU Leuven, University of Leuven, 3000 Louvain, Belgium

8 Department of Imaging and Pathology, Laboratory of Translational Cell and Tissue Research, KU Leuven, University of Leuven, 3000 Louvain, Belgium

9 University of Texas Southwestern Medical Center, Simmons Comprehensive Cancer Center, Dallas, TX, USA 